\title{
Culture Circle as a Teaching Approach in the Education of Teenager Health Multipliers on Leprosy Awareness
}

\author{
Estela Maria Leite Meirelles Monteiro ${ }^{1,2 *}$, Amanda Araújo das Mercês ${ }^{3}$, \\ Amanda Carla Borba de Souza Cavalcanti ${ }^{3}$, Ana Márcia Tenório de Souza Cavalcanti ${ }^{1}$, \\ Ana Catarina Torres de Lacerda ${ }^{3}$, Rosália Daniela Medeiros da Silva², \\ Andrea Rosane Sousa Silva1, Waldemar Brandão Neto

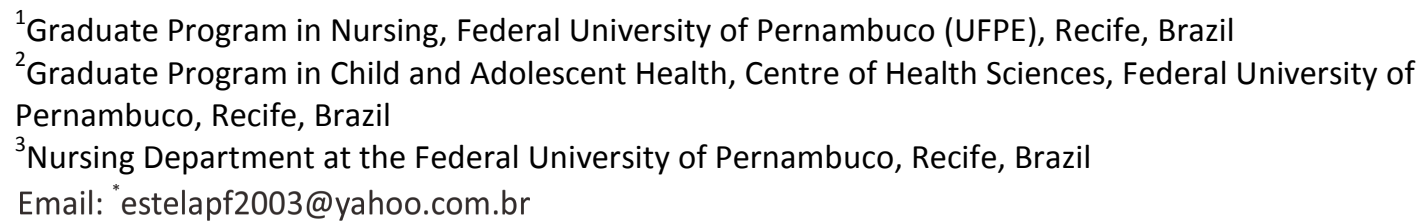

Received 13 October 2015; accepted 28 December 2015; published 31 December 2015

Copyright (C) 2015 by authors and Scientific Research Publishing Inc.

This work is licensed under the Creative Commons Attribution International License (CC BY). http://creativecommons.org/licenses/by/4.0/

(c) (i) 0pen Access

\begin{abstract}
Objective: The study aims to evaluate the use of a teaching method proposed by Paulo Freire, Culture Circles, in the education of teenagers multipliers on leprosy awareness. Methods: It is an action-research study with a qualitative approach developed in a public school in Pernambuco, Brazil. Five Culture Circles were conducted involving the participation of 26 teenagers. The followings were used as data collection tools: observation, field notes, photography and filming. Results: The educational intervention on health addressed the following topics: 1) Definition and transmission of leprosy; 2) Characteristics and diagnosis of leprosy; 3) Treatment of leprosy; 4) Aesthetics, prejudice and mental health related to leprosy; and 5) Planning of educational activities for teenagers as health multipliers on leprosy awareness. The educational action on health provided this age group to perceive themselves, act as political subjects in the development of Culture Circles, and act as protagonists in the dissemination of knowledge on leprosy. Conclusions: This study highlights that the application of active methodologies, such as Culture Circles, is able to encourage the engagement of young people in community empowerment and bring together health professionals and the school community in an intersectoral work in order to develop action strategies involving the promotion of health in the context of neglected diseases such as leprosy.
\end{abstract}

${ }^{*}$ Corresponding author. 


\section{Keywords}

\section{Adolescents, School Health, Leprosy Awareness, Culture Circles, Health Promotion}

\section{Introduction}

Leprosy is an infectious disease transmitted by the contact with untreated people or people with its transmissible forms. Today, it still represents a serious public health problem in Brazil and in developing countries. It is a condition that affects the lives of people more in a psycho-emotional sense than in health impairment due to the constant threat of prejudice, suffering, abandonment, deformity and psychosocial problems [1].

Inequalities, determinants and socially decisive aspects portray the epidemiological data on leprosy, which leads us to think about how health policies still need to be contextualized considering the culture, customs, socio-economic aspects and the disease's own behavior in each territory [1] [2].

In Brazil, the occurrence of new leprosy cases is increasing, mostly between the 10 to 15 age group. These cases are directly related to active transmission focuses and socioeconomic conditions. It is known that the most vulnerable populations are in less favored areas and since they are closely related to endemicity of the region, they have a great relevance for the epidemiology of the disease [3].

Considering cases of leprosy in Pernambuco, it occupies the tenth position in the coefficient of detection of this disease in Brazil. 36 cases in each group of 100,000 Pernambuco inhabitants are diagnosed with the disease and may suffer some sort of disability in the future, with often irreversible physical and psychological consequences. When analyzing it within the state according to its regions, the metropolitan area of Recife concentrates 55\% of cases of the disease. Of cases classified as new, 27\% already have disease consequences with regard to developmental disabilities. Within the Northeast region, Pernambuco occupies the third position with a higher leprosy detection rate, second only to Maranhão and Piauí. It is estimated that there are 14 cases per 100,000 aged under 15 in the state of Pernambuco [4].

There is not a specific form of prevention of leprosy, but there are measures that may prevent new cases, such as early diagnosis and treatment, monitoring of contacts and effective actions of health education. Leprosy diagnosis and the correct treatment without interruptions have a great importance in the prevention of physical disabilities. Prevention is primarily made through guidelines for self-care, psychologic and social support, measures that reduce prejudiced behavior towards people with leprosy and encourage family and friends not to repel patients by minimizing or preventing possible sequelae [5].

Understanding the epidemiology and the clinical characteristics of leprosy patients is paramount to design actions addressing the needs of these patients. They are developed together with the population and managers through social control and drafting of effective public policies on the activities of disease prevention and health promotion of the population affected [1].

In this context, there is a need to understand the dynamics of the disease by the teenager, since this stage of life is characterized by a period marked by a set of socio-psychological transformations. It leaves the young person exposed to a model of life until then unknown, full of uncertainties and insecurities that make it more vulnerable to situations of personal and interpersonal conflicts and establishing at the same time behavioral patterns that will become traces of its personality [6].

For a teenager who is in a phase of changes and adaptations, the beginning of a disease such as leprosy has negative repercussions such as truancy, depreciation of self-image with consequent change in the self-esteem and self-exclusion from the social environment. The person may become sad and without encouragement to perform daily activities, which is emphasized by the stigmatizing nature of the disease [7].

In this sense, social devices play a fundamental role in helping teenagers to face different situations. Most important is the role of the school. Upon recognizing the importance of this environment, the school has constituted a fruitful scenario for intersectoral actions between education and health with a focus on educational strategies to promote the health of this age group. The potential of teenagers to act as disseminators of knowledge in their family and social context should also be considered.

In order to establish strategies that promote the health of the teenage population with a focus on prevention 
and control of leprosy, there is the need to develop health education actions based on active methodologies, which provide a collective knowledge committed to social transformation. In this context, Culture Circles permeate a participatory educational experience with an emphasis on dialogue, autonomy and interaction between the popular and the scientific knowledge. It is a fruitful field for action-reflection-action in the preparation of a systematic proposal for an emancipatory health education [8].

Culture Circles are a teaching tool that breaks the curricular rigidity of academic formalism and provides necessary conditions for the actors involved—students and teachers - to feel familiarized to discuss significant issues for both groups, disregarding issues pre-fixed by a static curriculum regulation. The Culture Circle leads to critical thinking and different understandings on the part of its participants. It also enables a cognitive effervescence, involving problem-situations inherent to a same cultural universe. Thus, it constitutes a favorable arena for a group, with an in-depth process of communion around mutual learning, to produce knowledge from the elements of its culture [9].

Within the presented context and the experience of the authors in health education actions with Culture Circles, this study aims to evaluate the implementation of Culture Circles as a teaching approach in the education of teenagers multipliers on leprosy awareness.

\section{Methods}

It is an action-research study with a qualitative approach [10], based on the Paulo Freire Method: Culture Circles. For the development of the action-research, it was necessary to reconcile the role of the researcher and the animator of the Culture Circles, establishing an interaction with school teenagers, social actors of the study, determining a research collaboration with broader processes of educational activities and collective construction of knowledge. The choice of the Culture Circle as a theoretical and methodological framework in the development of educational intervention in health was established in order to provide teenagers to perceive themselves and act as agents of change regarding situations of vulnerability experienced in the community [11], inviting them at the same time to take the lead of disseminating knowledge on leprosy awareness.

The study was developed from August to November 2013 in a public school in the municipality of Camaragibe-PE, Brazil, which offers elementary school I and II. For the selection of the 26 teenagers in the study, the intentional sampling technique was used. The following inclusion criteria were adopted: 12 - 18 years age group of both sexes regularly enrolled in the mentioned school and teenagers showing a personal interest to actively participate in the health educational proposal.

The educational intervention occurred with the implementation of Culture Circles, in which the data produced in the group were recorded. For this collection of data, besides the researcher and animator of the Circle, there was the participation of other components with specific tasks such as filming, photographic record and taking of field notes.

There were five Culture Circles, each lasting two hours, which took place in the auditorium and in the school yard. The educational intervention addressed the following topics: 1) Definition and transmission of leprosy; 2) Characteristics and diagnosis of leprosy; 3) Treatment of leprosy; 4) Aesthetics, prejudice and mental health related to leprosy; and 5) Planning of educational activities for teenagers as health multipliers on leprosy awareness. To conduct the educational intervention in health, eight cyclical, inter-related phases were adopted as proposed by Monteiro and Vieira [8], adapted from the Paulo Freire method, as shown in Figure 1.

The previous knowledge phase was intensely experienced by the authors and was essential to the planning of the Culture Circles. It required an initial insertion of animators/researchers into the school scenario to raise and record cognitive, socio-cultural and psycho-emotional issues that involved the reality of adolescents participating in the Circles and the previous knowledge about leprosy.

For the analysis of the data, the data triangulation method [12] was used in order to achieve a greater validity and reliability of qualitative data. The organization of empirical material occurred with the detailed description of all the events of the Culture Circle through the transcription of the information collected with speeches record in full, narration of information contained in field notes, transcription of the filmed material ordered by narration and discussion, following the sequence of the Culture Circles. The analysis and interpretation synthesis occurred in a dialogue with the related literature and the experience of educational action, from which the cultural meanings on the approach to leprosy emerged. 


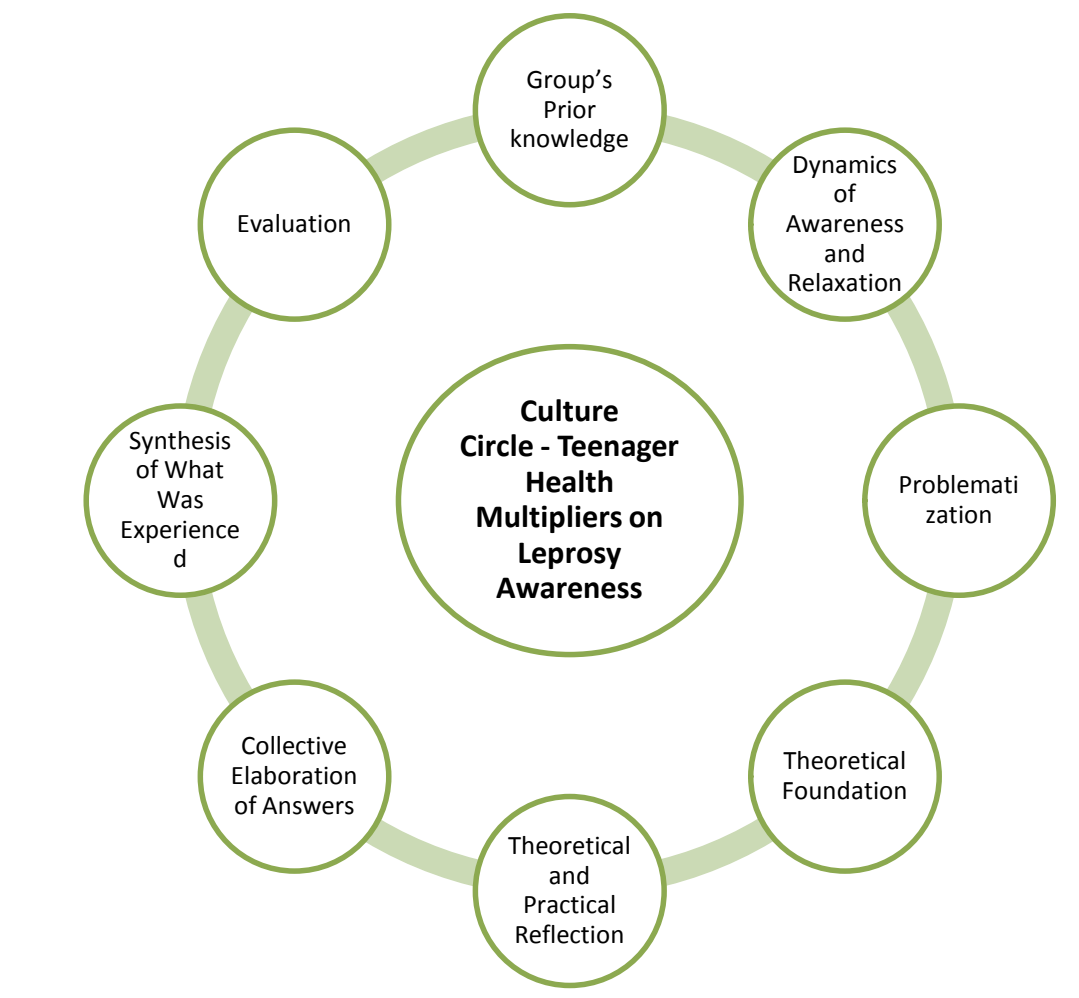

Figure 1. Phases of the Paulo Freire Method as proposed by Monteiro and Vieira (2010) and used in this study.

The study followed the advocated by the resolution no. 466/12 of the National Health Council [13], with the approval of the Ethics Committee of the Health Sciences Center of the Federal University of Pernambuco by the CAAE record (Presentation Certificate for Ethics Considerations) No. 16095013.5.0000.5208.

\section{Results}

The planning of educational activities took into account the desire and expectation of adolescents, and approached researchers and school management in a collaborative work of health promotion. The presentation of the results obeyed the order of the development of phases of each Circles, which outlined the educational process in the education of teenagers multipliers of health on leprosy.

All adolescents live in the community surrounding the school, considered of low economic status. As for the socio-demographic profile of the participants, it is described in Table 1.

\section{1) The first Culture Circle dealt with the theme Definition and transmission of leprosy.}

The awareness dynamics provided an integration among teenagers, where everyone was arranged in a circle. A person who was inside the circle should leave and walk around to choose a participant. This should tell its name and a characteristic with the first letter of its name, leaving to the person chosen the ability to follow up the activity.

The Problematization brought the following generative question: What do you understand about leprosy? Each teen was asked to answer the question with a drawing and then explain its meaning. Then, a poster was designed with the collective production of drawings. Most teenagers drew faces with expressions of sadness and doubt represented by question marks. Of the 26 teenagers, only three had some knowledge about the disease because they had experienced cases in the family or had access to posters on leprosy at health centers. They expressed this knowledge by producing drawings representing people crying with spots on the body.

Regarding the theoretical foundation, a contextualized scientific content was presented using a flipchart with colorful and simple illustrative photos and a clear language so that they could deepen the understanding of the disease and its means of transmission. 
Table 1. Characterization of the demographic data of the study sample.

\begin{tabular}{|c|c|}
\hline Variables & Adolescents $(\mathrm{N}=26) \%$ \\
\hline \multicolumn{2}{|l|}{ Gender } \\
\hline Female & 80.8 \\
\hline Male & 19.2 \\
\hline \multicolumn{2}{|l|}{ Age } \\
\hline 12 years & 19.2 \\
\hline 13 years & 50.0 \\
\hline 14 years & 30.8 \\
\hline \multicolumn{2}{|l|}{ Religion } \\
\hline Cattholic & 57.7 \\
\hline Evangelical & 34.6 \\
\hline Referred not have & 7.7 \\
\hline \multicolumn{2}{|l|}{ Who do you live with } \\
\hline Parents & 80.8 \\
\hline Mother and Stepfather & 11.5 \\
\hline Mother & 3.8 \\
\hline Father & 3.8 \\
\hline \multicolumn{2}{|l|}{ Those who work } \\
\hline Parents & 23.1 \\
\hline Father & 50.0 \\
\hline Mother & 19.2 \\
\hline Parents and brothers & 7.7 \\
\hline \multicolumn{2}{|c|}{ How many people live in the residence } \\
\hline 3 to 4 people & 50.0 \\
\hline 5 to 6 people & 42.3 \\
\hline 7 or morepeople & 7.7 \\
\hline
\end{tabular}

The theoretical and practical Reflection was the resume of the guiding question seeking to identify the knowledge and opinions of teenagers on the theme, thus creating a relation between the experienced reality and the contextualized content. At this phase, teenagers expressed that the discussions produced in the Circle led to changes and advances in the knowledge acquired. They reported that they previously believed that the spread of leprosy occurred by hug, kiss, handshake, touching skin injuries and/or that it was a sexually transmitted disease.

For the collective preparation of answers, it was requested that each teenager said a word to define leprosy. Two categories were identified: 1) Teenagers expressed words of encouragement such as perseverance, determination, strength, focus, faith. 2) Teenagers also portrayed an awareness regarding the prejudice and the exclusion experienced by people who have leprosy represented by the words sadness, exclusion, prejudice.

In the synthesis phase, a poster/mural was prepared with drawings, encouragement sentences, words that retake the theme addressed in the Circle.

At the time of the evaluation, an informative booklet containing crossword puzzles related to the theme of the circle was delivered to the teenagers. It was answered by the participants complementing the knowledge addressed in the Circle.

2) The second Culture Circle dealt with the theme Characteristics and Diagnosis of Leprosy.

In the awareness-raising dynamic, teenagers chose magazine pictures that portrayed similarities or differences in relation to the theme considering the popular knowledge. 
In the questioning phase, the following question was addressed: What are the characteristics of leprosy? How can it be diagnosed? It stimulated the identification of knowledge, doubts and concerns of the participants.

For the theoretical and practical basis, an album-series exploring the clinical and diagnostic features of the disease was used. At the theoretical and practical reflection phase, a playful activity regarding the questions about leprosy was conducted. They were addressed in this Circle. The playful activity was the application of a board game, for which the group was organized into three subgroups with a choice of one representative for each of them. The rules were: each participant rolls the dice and move the respective number of spaces. In some spaces, there are questions. If the player correctly answers the question, it remains in that space. If the player wrongly answers the question, it moves back two spaces. Upon reaching the end of the board, the player drew a question and answered it.

During the collective preparation of answers phase, teenagers resumed the initial questioning, allowing the re-elaboration of a more scientific-based answer. Then, educational materials were delivered containing a list of the addressed knowledge, as well as the Internet address of the website and the Facebook group, a virtual environment to streamline communication and clarification of doubts.

In the synthesis phase, the expectations of multipliers in relation to the issue addressed during the round were taken into account, clarifying their questions about the function of the multiplier and the relevant topic. The group demonstrated an acceptance of the methodology applied to the association of leaflets and the interaction with social networks.

The evaluation of the Circle was conducted through a dynamic in which teenagers reported what they felt about the development of the Circle phases, opting to "like it" or not. The evaluations were positive, since all have chosen to mark "like it". An open dialog was conducted for teenagers to express the appreciation of the dynamics presented.

\section{3) The third Culture Circle addressed the topic Leprosy treatment.}

The Circle began with an awareness dynamic, in which each student received a sheet of paper and a pencil, and then was asked: What do you want your friend that is at your right to do? They answered the question and signed their names. Then, after everyone had delivered the sheets of paper, the facilitator asked each person to do what the friend asked for and finished by explaining the objective of the dynamic: What I do not want for myself, I do not do to others.

At the problematization phase, the students were divided into five groups and received a cardboard and colored pencils. Each group was asked to discuss how to treat leprosy and register on cardboard what the group thought. Afterwards, each group presented their poster. The following statements were recorded:

The treatment is expensive, but in some cases, the health center provides it. (E1)

If the person has no money to buy the medicine, it can seek it at the health center (E2).

In some cases, people seek the medicine at the health center, but sometimes it does not have the medicine.

Then, the person has to buy it, but one has no money and one leaves the disease there [...] (E3).

$[\ldots]$ there is indeed treatment and the medicine is free (E4).

Our group thinks the treatment is done by drugs in pills and it is prepared in the health center and it is free (E5).

At the theoretical basis phase, a flip chart was used to explain the treatment of the disease. The medication blister pack was presented, differentiating the paucibacillary and multibacillary method for child and adult treatment. Supervised doses were highlighted. They are at the top of the blister pack and should be taken in the presence of nurses. The continuous medication can be used at home. During the explanations, several questions emerged, such as:

Do other drugs that are not taken in front of the nurse have to be taken every day? (E5)Can people with anemia take the medicine? (E8)

Is there an illness that interferes with it, and you cannot take the medicine? (E11)

If the person is thinking that it has the disease and the health center is closed, can I go to a hospital? (E19)

If one takes the red medicine and the pee color changes, must one continue using the medicine? (E24)

All doubts were clarified, and the importance of not interrupting the treatment was stressed. The side effects of medications and other necessary precautions during treatment were also explained. It was stressed that leprosy is curable. 
To support the theoretical and practical reflection, a game in which students were divided into five groups was elaborated. A blister pack with an increased size, made of rubber produced by the facilitators, was put on the ground. The dynamic was to roll a dice and walk on the pills. The person that fell on top of a pill with a question should answer it correctly to advance. The questions addressed the treatment of leprosy.

For the collective elaboration of answers, the facilitator of the Circle asked several questions about the treatment of the disease, obtaining a consistency in the responses given by the group.

At the synthesis phase, the facilitator used a parody of the treatment of leprosy and distributed the lyrics to students so everyone could sing.

In the evaluation phase, the teenagers expressed that they liked the different learning methods using music and educational games, highlighting the importance of using a playful method to facilitate learning, as was evident in some opinions:

[...] so we learn playing [...] (E17)

[...] it was one of the best, because there were many different activities such as music and games on the same day $[. .$.$] (E26).$

\section{4) The fourth Culture Circle addressed Mental health and Prejudice towards leprosy.}

The dynamics of awareness and casualness aimed to educate teenager participants in relation to situations of stigma and prejudice experienced by people with leprosy. In the awareness dynamics, it was presented to every teenager, following its placement in a circle, a hat that had a mirror on the inside reflecting the teenager's own face, and another hat with a picture of an individual with a leonine face characteristic of leprosy in an advanced stage without treatment. Then, teenagers were asked to talk a little about each image.

A dialogue followed, in which participants expressed their feelings and opinions regarding the experienced activity. The following was reported: conflicting feelings of insecurity and fear at the prospect of interacting with people with leprosy. This led the group to think about how society can be prejudiced and insensitive, having an excluding attitude and potentiating negative feelings towards a person with leprosy.

The problematization led to a discussion and a broad concept of health and disease, in which health was defined as the balance between physical, psychological and social well-being. This concept was discussed considering that leprosy affects the individual in its entirety. In preparing the understanding of prejudice, the predominance of the society's posture was evidenced based on ignorance and lack of knowledge about the disease.

In the theoretical basis, the video series-Heirs of Prejudice-Part 2 was presented. It is available at the following address: https://youtu.be/sOPwb_EG6E8. It portrays in the speech of former patients the isolation and social prejudice evidenced by the compulsory relocation of patients to the Colônia de Mirueira, located in the State of Pernambuco, Brazil.

In the theoretical practical reflection, teenagers demonstrated a visible sensitivity to deepen the discussions on the stigma experienced by patients with leprosy considering the construction of knowledge grounded on the prior knowledge plus the reports presented by protagonist patients of their exclusion stories for having leprosy.

Teenagers highlighted that people with leprosy needed support to continue the treatment and that in addition to physical problems resulting from the pathology, patients with the disease are emotionally shaken. This contributes to a feeling of low self-esteem and contribute to a greater difficulty in adherence to drug therapy.

At the time of the collective elaboration of answers, the teenagers were encouraged to reflect on the problem-situation raised earlier in the Circle regarding exclusion and prejudice situations experienced by leprosy patients. Discussions in the group fostered the development of broader thoughts, triggered by an articulated composition of responses by the teenagers.

In the synthesis of what was experienced, the materials were made available for teenagers to collectively produce a poster with the knowledge acquired during the Culture Circle. They explained with ease and with a critical reflection that prejudice is wrong, that the incentive to treatment is important and that a carrier of the disease can lead a normal life provided it is treating the disease regularly.

In the evaluation stage of the Circle, the knowledge about leprosy and prejudice was evaluated. Teenagers demonstrated a fluency on the subject. They answered all questions with ease and security, as well as designing posters that encouraged an unprejudiced conduct towards people with the disease. The learning triggered by the construction of collective knowledge and social responsibility to seek knowledge about leprosy aiming to overcome a prejudice posture that is fruit of ignorance and lack of solidarity was notorious. 
5) The fifth Culture Circle addressed the Planning of an educational action by teenagers as multipliers in leprosy awareness.

In the dynamics of awareness/casualness, five sheets of craft paper were scattered on the floor. In each, a name of a playful activity was written: theater, dance, music, drawing and puppet theater. They were asked to group themselves according to their skills. The largest group went to theater, followed by drawing. Only one person chose dance, two chose music and none chose puppet theater.

The problematization phase presented a discussion of the presentation method to be used by teenagers as multipliers on leprosy awareness. When considering the proposal of a group action, the teenagers listed theater as a form of popular expression regarding health.

The theoretical basis was a brief explanation of the elaboration of the scenic text, construction of the characters, setting the stage, spoken and unspoken communication and interaction with the public.

At the time of theoretical and practical reflection, the initial question was resumed with the definition of the play's central idea by the multipliers. The facilitators assisted in the composition of the text, with the lines of the characters that each teenager was responsible for playing.

The play told the story of a teenager who had stains throughout the skin and so friends did not want to approach her. Then, the teacher notes that she has a sad countenance and advises her to talk to her mother in order to take her to the Family Health Unit. When she is taken to the health service, the teenager sees a nurse who carries out an inspection and an evaluation of the sensitivity of the stain. With the reception, necessary guidance about leprosy and necessary referrals, she is happy to know that it is a curable disease and has a treatment offered for free.

For the collective preparation of answers, teenagers resumed the preliminary question, defining the knowledge about their characters and lines, as well as setting the stage, asking the facilitators of Culture Circles for another meeting to correctly play their character.

In synthesis phase, the importance of acting as multipliers and everything that was experienced was emphasized. Finally, in evaluating the Circle, facilitators questioned what they thought about the Circle and obtained the following statements:

[...] I'm happy with what I learned [...] (E15)

[...] I'm feeling very special to be part of the project and to be able to say what I've learned to other teens [...] (E18)

The teenagers acted as multipliers in leprosy awareness in their school (municipality of Camaragibe) and in other public schools in the Distrito Sanitário V (Municipality of Recife, Pernambuco, Brazil), which had no coverage of the Health in School Program during the National Pre-Campaign on Leprosy and Geohelminth Infections held in August 2013.

\section{Discussion}

Schools are a favorable scenario for health education interventions with teenagers, providing an intersectoral action to promote health for this age group. As a place of unique opportunities in the development of educational activities, schools should invest more in activities that promote health in partnership with institutions linked to health services due to their strategic role in the development of actions and in the implementation of educational programs that could improve health conditions such as the Health in School Program ("Programa Saúde na Escola”, PSE). Therefore, such actions must value partnerships for a participatory, interdisciplinary cross development, and provide playful and interactive processes [14].

As an active methodology, the Culture Circle favored the learning process upon ensuring the autonomy and the main role of adolescents as multipliers in health on leprosy awareness, changing the prejudice attitudes towards individuals with the disease. The organization of teenagers in a circle maintains a possibility of dialog in the process of building a collective, shared and contextualized knowledge, which led students to an inner journey towards personal, formal, informal experiences. The development of Culture Circles requires the work of animators/facilitators in the collective construction of knowledge, providing a link between the popular and the scientific knowledge.

Creativity is of fundamental importance to the Culture Circle coordinator. It must seek to grasp the totality of human expressions that are embedded in the cultural universe of the group, considering everything that the body produces and signals such as gestures, language expressions, attitudes and silence [9]. 
The steps that guide the Culture Circles as proposed by Freire are composed of Thematic Research, The matization and Problematization. In this study, we used the phases as proposed by Monteiro and Vieira [8], which systematically address the phases proposed by Freire in youth and adult literacy, explaining in detail how the health educator might base its planning during an educational activity.

The Thematic Research requires that the facilitator/animator consider the prior knowledge of teenagers, the Thematization of the interests and their demands regarding the contents to be addressed. The Problematization causes participants to express their experience and/or opinion before a contextual questioning of a topic, allowing the construction of a dialogical understanding of the cultural universe of teenagers. Freire [15] defined culture as the way people understand and express their world and how people can understand themselves in their relations with their world.

The study requires to "take a serious and curious attitude towards a problem" ([16], p. 58). Thus, the Problematization phase, proposed by [8], in order to be applied to health education activities, emerges from generating issues proposed by animators/researchers, leading to an immersion in the subject from the experiences of the group, full of personal and collective meanings intrinsic to the involvement of each member in the learning process. The teaching and learning in the Circles are indivisible, dialectical interactions, providing a unique and dynamic process. According to Freire [17], only authoritarian teachers and educators deny solidarity between the act of teaching and the act of being educated by the students.

For the construction of new knowledge, the Problematization phase does not end in itself. The animator must consider the characteristics of the groups participating in Circles and use teaching techniques such as educational games, videos, pictures, drawings and/or dramatization, providing a dynamic and enjoyable learning.

The application of a Culture Circle can provide an intense flow of critical, reflective and mobilizing knowledge committed to a renewed practice in Health education [16]. According to Paulo Freire, idealizer of the Culture Circles, the use of this pedagogical proposal is essential to the construction of health education strategies, enabling to assume that teenagers have knowledge, values, principles and feelings and, at the same time, understanding of their responsibility to transform reality [8].

The educational intervention, developed during the Culture Circles, included themes that addressed specific knowledge on epidemiological and physical characteristics, emotional factors and social and cultural aspects of leprosy, as well as diagnosis and treatment.

The proposed Culture Circles establish a partnership relation between multipliers and community groups with the understanding of health as a product of real social conditions and the commitment to health promotion actions [8]. The contextualized learning of the subject by teenagers consolidated an empowerment posture essential to elaborate a proposal for educational intervention as multipliers in health.

A key issue for educational activities on health awareness is not in perfecting techniques of sending a message or persuading people, but in rethinking the assumption according to which the existence of scientific information in the received messages is sufficient to increase the competence and/or the freedom of decision in order to incorporate, in everyday life, the appropriate or desired behavior in its autonomy to maintain the health or care of oneself [18] and one's community, thus leading to a change in behavior and perceiving educational activities as a process of forwarding information where the listener is a passive learner.

The feelings and anxieties associated with this ancient disease, such as fear, shame, guilt, social exclusion, rejection and anger, are internalized in individuals with leprosy. The prejudice remains rooted in our culture and society mainly due to the lack of access to information, causing a great suffering to individuals with the disease [19].

Some results evidences the prejudice of people against individuals under treatment or those who are already cured of leprosy due to a lack of knowledge. While there are no effective educational activities aiming to disseminate information about leprosy contagion means, the society will continue to create means to understand and protect themselves from it, symbolically repelling from its contagion [20].

To overcome the challenge of making health education activities more effective, it is necessary that such actions be based on concern for each other and one's individual needs, favoring care and not directing, but respecting the existence and the essence of the human being [18].

Health promotion activities using active methodologies contribute to a critical reflection of actions and strategies that could culminate in promoting and maintaining interventions regarding the quality of life of teenage students [21]. 


\section{Conclusions}

In the development of teaching and learning methods with teenagers, it is essential to consider the peculiar characteristics of growth, physical, psycho-emotional, social and cultural developments of this age group. In this sense, the Culture Circle embraced the universe of the teenager in its entirety, bringing together motivation and learning, joy and knowledge, reflection and commitment, challenges and concerns with a desire for change. This culminated in the full participation of teenagers in a process of construction and reconstruction of knowledge and attitudes related to leprosy.

The school scenario was an environment favorable to health education interventions from an intersectoral action, which integrates education and health in a proactive proposal for a comprehensive care towards the teenager in both its cognitive development and the good exercise of one's behavior. Thus, investment in educational prevention programs, supported by emancipatory paradigms, can promote the work of teenagers as protagonists in discussions of public health issues, and developing of coping strategies for the prevention of leprosy, allowing intervene in conditions of health, life and care in the community.

In this sense, health education knowledge about the leprosy was essential to face the stigma and prejudice by establishing a human look in caring for each other and the possibilities of formation of support networks to promote an early detection and the treatment of leprosy. The study also reveals the importance of strategic planning, at the management level, of actions promoting health that allow bringing health services closer to the school community when attending the needs of teenagers and their families in the context of neglected diseases such as the leprosy. In addition, it stresses the need for further research that uses the Culture Circle method with different age groups and with other themes.

\section{Limitations}

As this is a qualitative intervention study with the local development of a critical and awareness-educational action, involving a sample of adolescents with peculiar characteristics, the results allow not being generalized to the population.

\section{References}

[1] Souza, V.B., Silva, M.R.F., Silva, L.M.S., Torres, R.A.M., Gomes, K.W.L., Fernandes, M.C. and Jereissati, J.M.C.L. (2013) Epidemiological Profile of Leprosy Cases in a Family Health Center. Brazilian Journal in Health Promotion, 26, 110-116.

[2] Magalhães, M.C.C. (2007) Diferenciação territorial da hanseníase no Brasil. Epidemiol Serv Saude, 16, 75-84.

[3] Fernandes, C., Beltrão, B.A., Chaves, D.B.R., Leandro, T.A., Silva, V.M. and Lopes, M.V.O. (2013) Assesment of the Resilience Level of Adolescents with Leprosy. Revista Enfermagem UERJ, 21, 496-501. http://www.e-publicacoes.uerj.br/index.php/enfermagemuerj/article/view/10021/8133

[4] Secretária de Saúde do estado de Pernambuco. Programa Estadual de Vigilância, Prevenção e Controle da Hanseníase (2013) Boletim Epidemiológico-Hanseníase.

http://portal.saude.pe.gov.br/programa/secretaria-executiva-de-vigilancia-em-saude/programa-estadual-de-vigilancia-pr evencao-e

[5] Pereira, D.L., Brito, L.M., Nascimento, A.H., Ribeiro, E.L., Lemos, R.K.M., Alves, J.N. and Brandão, L.C.G. (2012) Estudo da prevalência das formas clínicas da hanseníase na cidade de Anápolis-GO. Ensaios \& Ciência, 16, 55-67. http://www.redalyc.org/articulo.oa?id=26025372004

[6] Neto, G.X., Rosemiro, F., Dias, A., Rocha, M.S. and Cunha, I.C.K.O. (2007) Gravidez na adolescência: Motivos e percepções de adolescentes. Revista Brasileira de Enfermagem, 60, 279-285. http://dx.doi.org/10.1590/S0034-71672007000300006

[7] Ponte, K.M.A. and Ximenes Neto, F.R.G. (2005) Hanseníase: A realidade do ser adolescente. Revista Brasileira de Enfermagem, 58, 296-301. http://dx.doi.org/10.1590/S0034-71672005000300008

[8] Monteiro, E.M.L.M. and Vieira, N.F.C. (2010) Educação em saúde a partir de círculos de cultura. Revista Brasileira de Enfermagem, 63, 397-403. http://dx.doi.org/10.1590/S0034-71672010000300008

[9] Peroza, J., Silva, C.P. and Akkari, A. (2013) Paulo freire e a diversidade cultural: Um humanismo político-pedagógico para a transculturalidade na educação. Reflexão e Ação, 21, 461-481.

[10] Merriam, S. (2009) Qualitative Research: A Guide to Design and Implementation. Jossey-Bass, San Francisco.

[11] Monteiro, E.M.L.M., Brandão Neto, W., Lima, L.S., Aquino, J.M., Gontijo, D.T. and Pereira, B.O. (2015) Culture 
Circles in Adolescent Empowerment for the Prevention of Violence. International Journal of Adolescence and Youth, 20, 167-184. http://dx.doi.org/10.1080/02673843.2014.992028

[12] Flick, U. (2014) An Introduction to Qualitative Research. 5th Edition, Sage Publications, London.

[13] Brazil (2012) Resolution 466, Issued on December 12th, 2012. Discusses the Guidelines and Regulatory Standards of Research Involving Human Beings. National Health Council, Ministry of Health, Brasilia, DF. http://conselho.saude.gov.br/resolucoes/2012/Reso466.pdf

[14] Brito, A.K.A., Silva, F.I.C. and França, N.M. (2012) Programas de intervenção nas escolas brasileiras: Uma contribuição da escola para a educação em saúde. Saúde debate, 36, 624-632. http://dx.doi.org/10.1590/S0103-11042012000400014

[15] Freire, P. (2008) Education as the Practice of Freedom. 31th Edition, Paz e Terra, Rio de Janeiro.

[16] Linhares, F.M.P., Pontes, C.M. and Osório, M.M. (2014) Using the Theoretical Constructs of Paulo Freire to Guide Breastfeeding Promotion Strategies. Revista Brasileira de Saúde Materno Infantil, 14, 433-439. http://dx.doi.org/10.1590/S1519-38292014000400013

[17] Freire, P. (2011) Pedagogy of the Oppressed. 50th Edition, Paz e Terra, Rio de Janeiro.

[18] Paz, E.P.A. and Silva, M.C.D. (2012) Educação em saúde no programa de controle da hanseníase: A vivência da equipe multiprofissional. Escola Anna Nery, 14, 223-229. http://dx.doi.org/10.1590/S1414-81452010000200003

[19] Baialardi, K.S. (2007) O Estigma da Hanseníase: Relato de uma Experiência em Grupo com Pessoas Portadoras. Hansenologia Internationalis, 32, 27-36. http://www.ilsl.br/revista/imageBank/301-862-1-PB.pdf

[20] Palmeira, I.P., Queiroz, A.B.A. and Ferreira, M.A. (2012) Quando o preconceito marca mais que a doença. Tempus Actas de Saúde Coletiva, 6, 187-199.

[21] Moreira, R.M., Boery, E.M., Oliveira, D.C., Sales, Z.N., Boery, R.N.S.O., Teixeira, J.R.B., Ribeiro, I.J.S. and Mussi, F.C. (2015) Social Representations of Adolescents on Quality of Life: Structurally-Based Study. Ciência \& Saúde Coletiva, 20, 49-56. http://dx.doi.org/10.1590/1413-81232014201.20342013 